\title{
VALUE BASED MANAGEMENT AT SIEMENS - THE CLASSIC EXAMPLE REMAINS
}

\author{
Diana Claudia Cozmiuc \\ West University, Timișoara, Romania \\ diana.cozmiuc.record@gmail.com \\ loan Petrișor \\ West University, Timișoara, Romania \\ ipetrisor53@yahoo.fr
}

\begin{abstract}
The main objective of this paper is to check if value-based management in its classic design, 1980-2000, still works in the practice of one of its most prominent cases, Siemens. The paper also aims to describe value-based management in Siemens' practice 1998-2020. This should enable a comparison between theory and practice the paper targets. The research methodology is case study: literature review, empirical data analysis, conclusions based on comparison. The case study is exploratory and descriptive. The article relies on secondary evidence about Siemens during 1998-2020, selects the evidence that pertains to value-based management and constructs the Siemens case example. The article is based on a large body of evidence, where the statements about valuebased management are chosen based on their relationship to key words such as value, value drivers, value creation. The results may be the confirmation or denial of classic value-based management. The conclusion is that managing for Economic Value Added still works in the current business context. Other findings are Siemens' driver tree during 1998-2020 in thorough description.

Keywords: value-based management, Economic Value Added, value driver, performance metric, competitor benchmark
\end{abstract}

\section{INTRODUCTION}

Business excellence may be defined as measuring business performance improvements and value creation dynamics (Emerald, 2020), and Siemens is a classic case example for business excellence to be tested in the New Economy (Zhao, 2004). Performance management may be included in a value-based framework, which means performance indicators are aligned to the overarching goal of the firm value creation is (Copeland et al.., 1994). Value based management emerges in the 1990s as both a strategic management discipline and a financial management discipline. The first value-based management proposals stem from major consultancy firms along with the media disputed value indicators in the 1990s. 
There are two main stages in theorizing value-based management: the first proposals in value-based management, years 1990 - 2000, and the updates in value-based management based on the changes of the New Economy and on experience, since 2000. The first proposals in value-based management work hard to implement strategy effectively, solving implementation gaps argued as ground. Contemporary value-based management reconceptualizes strategic management from the value perspective, at all strategic management stages. Classic value-based management orients company decisions on value, via value indicators and value drivers. In value-based management philosophy, strategy creates value via value drivers. Value drivers are individual on company level. Value based management cases are similarly individual on company level, where literature treats every company as a case. Using value drivers, valuebased management links intrinsic value with strategy, and financial management with strategic management. Value based management has a generic framework that works for all companies and a tailored approach, value drivers, that is individual to each company.

\section{METHODOLOGY ELABORATION}

The goal of this article is check if classic value-based management is still a valid theory in the practice of a top corporation, Siemens. The article also aims to illustrate value-based management at Siemens during 1998-2020 and beyond. An explorative and descriptive case study works towards these objectives and tackles all major points in the practice of value-based management at Siemens. Using case study methodology, the research performs an extensive literature review and empirical data analysis about value-based management. The literature review captures the works of the consultants that proposed value-based management since the 1990s. This is classic value-based management. The literature review captures the most important achievements of value-based management related to managing for classic value indicators. The focus of the article is capturing the core logic of value-based management. Siemens is one of the most important world class cases in value-based management, deliberately admitting to using this strategic framework, recognized as such by value-based management consultants (Stern et al.., 2003) and by articles in scientific journals (Zhao, 2004). The logic of the case study, both in the literature review and in the empirical data analysis sections, serves the paper objectives. The Siemens case has been constructed based on secondary data in annual reports and other secondary data pertaining to Siemens. The data was chosen in relation to key words such as value-based management, value indicator, value driver, value creation, performance indicator. The selection was also made based on statements about corporate governance in annual reports. Since 1998, Siemens has explicitly implemented value-based management and coined its strategic statements in value creation. The case study explores, describes, analyses and induces value-based management at Siemens. The empirical data analysis focuses on 
value drivers, financial or non-financial performance indicators at Siemens. Value creation is analysed. The overall framework for value-based management since 1998 is induced. The exploratory nature of the case refers to the objective, checking if classic value-based management is still practiced by leading companies, and the answer is yes, as Economic Value-Added creation remains overarching goal. The case may serve as pilot or reference for other cases. It is relevant to academics because it confirms theory. It also has empirical value given by the importance of Siemens, for example as benchmark. The case is also descriptive and illustrative of value-based management in the practice of one of the leading companies in Europe. Its relevance to academics and practitioners alike is given mainly by the importance of Siemens as a company. Siemens is a powerful empirical example, which can be used as a lesson or benchmark about value-based management practice, which illustrates theory and highlights its practical functionality. The strength of the research is its holistic systems approach, where the strategic framework of the largest European engineering company for 20+ years is explored, analysed, induced, synthesized. This systems approach makes the case study unique and justifies the qualitative research method. The research finds Economic Value Added remains the overarching goal of Siemens' strategy. The research also finds that, since 1998 spanning beyond 2025, value-based management at Siemens has shared a common structure, the value driver tree. This structure is first the emerging Siemens strategy during 1998-2005, then gradually the deliberate strategy years that followed. Value drivers are the Siemens acumen and strategy's tools to create value.

\section{LITERATURE REVIEW - VALUE BASED MANAGEMENT}

Value based management begins with value indicators and goes on to build an entire organization (Ehrbar, 1998; Martin and Petty, 2000). The management program emerged in the 1990s, as an elaboration of value indicators. In the 1990s, several consultancy firms engaged in the war of metrics and proposed several value indicators: Shareholder Value Added for LEK Consulting (Rappaport, 1986), Economic Value Added for Stern and Stewart (Stewart, 1991), CFROI for Holt Associates (Madden, 1999), Cash Value Added for Holt Associates (Madden, 1999) or Boston Consulting Group (Boston Consulting Group, 2008), Total Shareholder Return for Boston Consulting Group (Boston Consulting Group, 2008). The new value indicators were conceived to correct old value indicators, such as Return on Investment, Return on Capital Employed, or Earnings Per Share, and are similarly computed based on the Profit and Loss Statement, the Balance Sheet, and additional information. These indicators are used for short-term and long-term financial analysis, for enterprise or for project valuation. At the roots of these indicators lies a Nobel awarded theory (Nobel Price Foundation, 1997), the net present value of discounted cash flow, a method of capital budgeting or valuation developed by Professors Merton Miller and Franco Modigliani 
(both Nobel laureates) in 1961 (Koller et al., 2005). Mc Kinsey argues that value-based management in the 1990s has made this approach popular (Koller et al., 2005). Since 1994 when Mc Kinsey has proposed value based management in the first edition of its book "Valuation", value is computed as discounted cashflow and is equal to the spread between return on invested capital (alternatively capital employed) and weighted average cost of capital multiplied with capital employed plus the book value of capital (Copeland et al.., 1994). These two equivalent formulas are Shareholder Value Added and long-term Economic Value Added, Market Value Added, plus the book value of capital (Damodaran, 2007). This is a company's, business unit's or project's intrinsic value to shareholders on capital markets. Alternatively, CFROI and Cash Value Added are intended as better computation. Were capital markets perfectly efficient, intrinsic value would be reflected in share price. As contemporary capital markets are best case partially efficient, Boston Consulting Group's Total Shareholder Return indicator adds market inefficiencies to intrinsic value and may be equivalent to the spread in share price plus dividends (Boston Consulting Group, 2008).

Value based management is the hallmark of management consultants, who engage with customers in setting up holistic management programs that create, propose, capture, deliver value. Several major consultancy firms: Marakon Associates, LEK Consulting, Stern Stewart, Mc Kinsey, Boston Consulting Group, Price Waterhouse Coopers engage in defining value and managing for value. Contemporary with the war of metrics, value-based management is elaborated based on the value discipline as a management program first defined by Mc Kinsey (Copeland et al.., 1994) and Marakon Associates (McTaggart et al., 1994; McTaggart and Gills, 1998). Accordingly, "the thinking behind value-based management is simple. The value of a company is determined by its discounted future cash flow. Value is created only when companies invest capital at returns that exceed the cost of that capital. Value based management extends these concepts by focusing on how companies use them to make both major strategic and everyday operating decisions. Properly executed, it is an approach to management that aligns a company's overall aspirations, analytical techniques, and management processes to focus management decision making on the key drivers of value." (Copeland et al., 1994). Alternatively, according to Marakon Associates (McTaggart et al., 1994, 1998), value-based management "is a combination of beliefs, principles and processes that effectively arm the company to succeed in the battle against competition from the outside and the institutional imperative from the inside. These beliefs, principles and processes form the basis of a systematic approach to achieving the company's governing objective". During the 1990s, several other definitions emerge. According to a first set of definitions, value-based management is focused on the overarching goal, shareholder value (Armitage and Fog, 1996; Bannister and Jesuthasan, 1997; Christopher and Ryals, 1999; Condon and Goldstein, 1998; Marsh, 1999; Ronte, 1998). This ties value-based management to corporate governance (Stern et al., 2003). Value based management is also viewed as a form of management via objectives, where management systems are 
aligned to the overarching value indicator and goal (Arnold, 1998; Black et al., 1998; KPMG, 1999; Leahy, 2000; Martin and Petty, 2000; McTaggart et al., 1994, McTaggart and Gilles, 1998). Definitions point to several management systems that are encompassed in the value based management concept: beliefs, principles and processes (McTaggart et al., 1994, McTaggart and Gilles, 1998); strategies, policies, performance, measures, rewards, organization, processes, people, and systems to deliver increased shareholder value (Black et al., 1998); systems, strategy, processes, analytical techniques, performance measurements and culture (Arnold, 1998); strategy, structure and processes (KPMG, 1999); performance reward (Martin and Petty, 2000); strategic planning, performance measurement and compensation (Leahy, 2000). Value based management is a holistic management approach (Boulos et al., 2001). Value based management is a management system conceptualized as a corporate governance framework which defines measures, incentives, instruments and control, which inflict a company's decisions to be consistent with the strategy to maximize shareholder value (Stern et al., 2003). During this period, 1990-2000, that defines value-based management, consultants engage with client companies to implement this management system and later publish overviews of their work with client companies (Copeland et al., 1994; Stern et al., 2003; Young and O'Byrne, 2000). The most successful value-based management implementors are awarded nobility titles, such as Sir Brian Pitman (Pitman, 2003). Of all value-based management definitions, the first, the most popular and the most enduring is Mc Kinsey's 1994-2015 (Copeland et al., 1994, 2000; Koller et al., 2005, 2010a, 2010b, 2015; Goedhart and Wessels, 2010).

In its first stage, 1990s-2000s, value-based management is described as a staged process (Ittner and Larcker, 2001). The primary stage is to choose the value indicator, the overall aspiration of the firm. The second stage is to select strategies and organizational design consistent with the value objective. In the third stage, value drivers are defined based on the value indicator definition. The fourth stage consists of action plans, selecting performance indicators, and setting objectives based on the priorities identified in the value driver tree analysis. In the fifth stage, actions plans are evaluated, and performance appraisals are conducted. Finally, objectives, strategies, plans and control systems are evaluated based on results and changed if necessary. In the view of the consultants who proposed value based management, LEK Consulting (Rappaport, 1992, 2006, 2009, 2011), Stern (Stern et al., 1995, 2003; Stewart, 1991, 1994, 2003, 2013), Mc Kinsey (Copeland et al., 1994; Copeland et al., 2000), Holt (Madden, 1998), Boston Consulting Group (2008), value based management ties all company's decisions to the overarching organizational objective, the value indicator, via decisional objectives, value drivers and uses complex means to make sure these decisions are of quality, are achieved, are rewarded.

In value-based management, key company decisions are focused on dedicated value drivers in a process called strategy valuation. The pioneer of value-based management studies, Rappaport (1986) ties value 
drivers to a firm's main decisions. The first and sine qua non decision is competitive advantage (Rappaport, 1986). Value based management is therefore subordinated to the CEO and is a strategic management discipline. In the years 1990 - 2000, consensus exists among value based management authors from consulting firms (Boston Consulting Group, 2008; Copeland et al., 1994; Rappaport, 1997, 2011; Stern and Chew, 2003; Stern et al., 2003; Young and O'Byrne, 2000) and valuation experts (Damodaran, 2006, 2007, 2011, 2012; Madden, 2010) that competitive advantage is the main driver of shareholder value. The remaining type of decisions that compute value are operational, investment or finance (Rappaport, 1986) and belong to financial management (Chew, 1998; Stern et al., 1995). Each decision is tied by Rappaport (1986) to a set of value drivers. Operational decisions relate to value drivers such as sales growth, operating profit margin, income tax rate. Investment decisions refer to fixed capital and working capital. Financing decisions are about equity and borrowings that sum up to net capital employed or invested. This stage of value-based management is consistent with basic financial management manuals, where net present value of discounted cash flow is used for capital budgeting and valuation (Kaplan Financial Publishing, 2012a, 2012b). This is the accepted capital budgeting theory in a certain environment. Put together, all decisions and value drivers in the planning horizon should compute long-term value, for example Shareholder Value Added. Long-term value gives the value of the strategy, strategy valuation, or the value of the company, business valuation (Boston Consulting Group, 2008; Copeland et al., 1994; Mankins and Steele, 2005; Rappaport, 1997, 2006, 2009, 2011; Stern and Chew, 2003; Stern et al., 2003; Young and O'Byrne, 2000). If the intrinsic value of a strategy is above zero, the strategy may be adopted; else, it will be rejected.

A major topic in both valuation and value-based management is mergers and acquisitions (Copeland et al., 1994, 2000; Rappaport, 1986; Stern et al., 2003). From a financial perspective, value-based management consultants argue that value indicators may be used to value mergers and acquisitions from both a seller's and buyer's perspective. Furthermore, value-based management is preoccupied with decisions to exit business units at the seller or to enter and integrate business units at the buyer. In internal projects, net present value of discounted cash flow is used to approve projects when it is above zero and accept them based on their ranking highest to lowest. From a financial management perspective, acquisitions create value when the present value of the new business unit exceeds the price paid, whereas exiting a business unit makes sense when the price received exceeds the net present value to this owner. Value based management is intended to facilitate mergers and acquisitions for both buyers and sellers from a holistic management perspective.

Since 2000, several consultancy companies have continued works on value-based management, managing for value, value creation, proposition, delivery, capture, measurement. At Mc Kinsey, the book "Valuation" is re-edited every five years (Copeland et al., 1994, 2000; Koller et al., 2005, 2010 a, 2010b, 
2010c, 2015); Boston Consulting Group publishes a yearly "Value creators report" since 1998 to date, which uses Cash Value Added and Total Shareholder Returns and argues the validity of these value indicators even in today's disruptive environment; formerly at Marakon Associates and now at Price Waterhouse Coopers, Favaro (Dominic and Favaro, 2006, 2007) argues value should lead strategy and points towards the importance of execution; so does Kontes (2010) for Marakon Associates. In some views, the principles of the capitalist enterprise, allocating capital to long-term value for shareholders, need focus today just like they did before (Stern, 2011). One such view is a major project between Mc Kinsey, KPMG, Earnst and Young, institutional investors, corporate CEOs and others about focusing capital on long-term - rather than short term, which causes underinvestment (FCLTGlobal 2019a, 2019b). Value based management can now be studied in the practice of major corporations (Stewart, 2013; Stern et al., 2003). Since 2000, major authors have emerged with new proposals about managing for value, the highlights of which are summarized as follows.

\section{EMPIRICAL ANALYSIS:}

\subsection{Value Based Management at Siemens}

Siemens' history dates to 1847 when it was founded by Werner Won Siemens. By 1955, Siemens had offices in Germany, St Petersburg and London. By World War I, Siemens held 168 offices in 49 countries. Today, Siemens is active in over 200 countries. Throughout time, Siemens and its competitor General Electric have been large conglomerates (CapGemeni, 2016). Most recently the portfolio of both corporations has changed and focused on a few core businesses (CapGemeni, 2016). Both Siemens and General Electric are among the largest software companies worldwide. Siemens is managed by the Managing Board and the Supervisory Board. The Managing Board comprises businesses, regions and corporate functions. Corporate functions are research and development, the central technology research and development department and the business specific departments; key account management, in charge of large or midsized, business or government customers; global supply chain management; 298 manufacturing facilities; support functions such as financial management, human resources management. Siemens is the largest European engineering corporation, with business in manufacturing, energy, building management, healthcare, transportation, smart cities on global markets. Siemens currently has 83 billion Euros sales and employs 377000 . Siemens' portfolio may be described in terms of businesses or key technologies electrification, automation or digitalization. Siemens offers customers products, services, solutions. Siemens is among the most innovative companies in the world, included as such in the Boston Consulting Group Most Innovative Companies in the past years (2012-2018). Siemens has used value- 
based management since 1998 to date as the guiding strategic management system. By the early 2000s, Siemens was one of the top world cases in value-based management, noted as such in the books of the Economic Value-Added consultancy firm author (Stern et al., 2003) and in Web of Science indexed journals (Zhao, 2004). During 1998 spanning beyond 2025, value-based management is Siemens' strategic management framework.

\subsection{Value Based Management and Siemens' Strategy}

In 1998, Siemens begins to implement value-based management (Siemens, 1998) in several stages which show progressive scope of the management systems deliberately subordinated to value creation. To begin with, value-based management is one of several management programs named top+ (Siemens, 1998), a ten-point program which comprises portfolio measures and financial and capital measures (Siemens, 1998, 1999). Value based management focuses all company activities on pursuing sustained value creation, and all decisions on a single performance indicator: creating Economic Value Added (Siemens, 1998, 2000). The goal of the program is sustainable growth in profitability (Siemens, 1999), a driver of Economic Value Added. Every system in the company is aligned to this goal: strategies, operations, activities, mergers and acquisitions, divestments, planning, management and controlling (Siemens, 1999). Siemens intends to achieve positive EVA until 2001 the latest (Siemens, 1999), and achieves this goal in 2000 (Siemens, 2000).

In the following years, the EVA centred value-based management is renamed Operation 2003 (2002), Siemens Management System (2003, 2004), Fit4More (2004-2007), Fit42010 (2008, 2009). As in Fig. 1 , these strategies are focused on increasing target margins. In 2002, managing for Economic Value Added is renamed Operation 2003 (Siemens, 2002, 2003). Economic Value Added remains a measurement for the success of each business group and the company as a whole (Siemens, 2003). In 2003, the top+ business excellence program is expanded into the Siemens Management System (Siemens, 2003, pp. 7). This is once again part of corporate governance with the aim to continually increase the value of the company (Siemens, 2003) or Economic Value Added (Siemens, 2003). Years that follow, the management programs that drive value creation holistically are called Fit4More (Siemens, 2006) or Fit42010 (Siemens, 2007). Yet again, the focus is on Economic Value Added (Siemens, 2007) or on the increase of the value of the company, which continues (Siemens, 2007). In 2010, the new corporate strategy is One Siemens (Siemens, 2010). With this strategy, Siemens' overriding aim is to continuously improve performance vis-àvis the markets and competitors while increasing its long-term value (Siemens, 2010). Long-term value is measured using discounted cash flow or Economic Value Added (Siemens, 2010). The Siemens One strategy is Siemens' strategy since 2010 and remains the same, restated in 2011 (Siemens, 2011), in 
2012 (Siemens, 2012), in 2013 (Siemens, 2013). In 2014, Siemens sets its strategy for the next years and perhaps decades (Siemens, 2014) and links it directly to value creation - for the short, medium and long term (Siemens, 2014). Siemens' short - term direction is to drive performance; its medium - term direction is to strengthen core; on the long term, Siemens will scale up, intensify its efforts to seize further growth opportunities and tap new fields. Siemens intends to create value sustainably (Siemens, 2014).

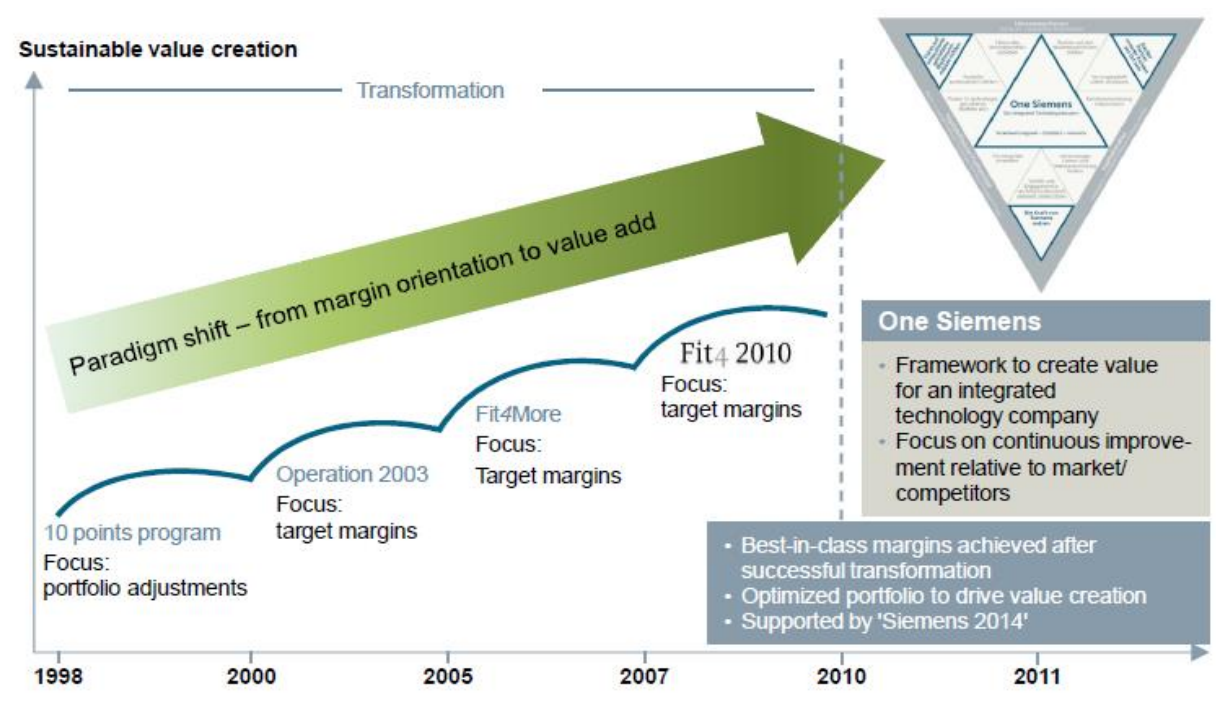

Drive performance

\section{Strengthen core}

Ownership culture: $>300,000$ employee shareholders

2015

2016

2017

2018

2019

2020

\section{FIGURE 1. SIEMENS' STRATEGY AND VALUE}

(source: Siemens, 2018)

The overarching strategic direction, driving performance, involves action towards business excellence, retailoring structures and responsibilities (Siemens, 2014). Strengthening core means organizing the company alongside core technological competences in electrification, automation and digitalization (Siemens, 2014); this will allocate resources rigorously among others. In Vision 2020, Siemens is to scale up and tap new EVA pools (Siemens, 2014). These strategic directions will lead to progressive increases in shareholder value. At Siemens, strategy integrates the key fields of corporate governance and sets the 
course (Siemens, 2014). Vision 2020+ is called ultimate value creation via market leadership. Siemens' strategies years 1998-2025 are exhibited in Fig. 1.

\subsection{Economic Value-Added Driver Tree at Siemens}

Since 1998 spanning beyond 2025, Siemens' management is centred on Economic Value Added. Economic Value Added is defined as the spread between return on capital employed, cost of capital, and business assets (Siemens, 1998). If this difference is positive the company creates value, if it is negative the company destroys value. On the long-run, Economic Value Added adds up to Market Value Added, the difference between a company's value on shareholder markets and its business assets (Thomas, 2013). Economic Value Added may pertain to current operations or new operations.

Value based management involves clear goals, concrete measures and rigorous consequences (Siemens, 1998). Siemens uses value indicators and value driver trees to assign goals to business units. Economic Value Added is assigned as target on corporate, business unit, investment centre, company level. Since 1998, when Siemens began to implement value-based management, the Managing Board has set goals to business units to create positive EVA. This means that, on individual business level, return on capital should exceed cost of capital, between $8-10 \%$ by business. The goals and their achievement are publicly communicated. Economic Value Added is broken down into value drivers, financial value drivers and nonfinancial value drivers. Since Fit4More, financial value drivers are called performance metrics and form the core of Siemens' strategy. They are also referred to as goals. With all Siemens' strategies since 2005: Fit4More, Fit42010, Siemens One, Vision 2020, Vision 2025, strategic directions are called non-financial value drivers and tied to performance metrics as clear goals. Throughout the implementation of valuebased management, Siemens' strategy comprises financial goals or value drivers and strategic directions, non-financial value drivers, tied to specific goals. The following paragraphs summarize Siemens' financial and non-financial value drivers and goals since 1998 reaching towards 2025.

Since 1998, when Siemens begins to implement value-based management, the Managing Board sets goals to business units to create positive EVA. This means that, on individual business level, return on capital should exceed cost of capital, between $8-10 \%$ by business. The goals and their achievement are publicly communicated.

Economic Value Added is broken into several value drivers (Siemens, 1998, 1999) that stem directly from the Economic Value-Added formula. One value driver is the ratio between NOPAT and business assets, which may be expressed by higher returns on business assets, increased productivity, profitable growth (Siemens, 1998, 1999). The higher the ratio the better. Another value driver is the capital cost rate, optimizing the cost structure (Siemens, 1998). Higher EVA will be created by low capital cost. The third key 
driver is business assets, to be managed by investment in value-creating operations; removal of business assets from value-destroying operations; asset management (Siemens, 1998). Economic Value Added is computed based on the Profit and Loss Statement, the Balance Sheet, data about the weighted average cost of capital. At Siemens (Thomas, 2013), the most important value driver is capital allocation. Investment in tangible assets, intangible assets and portfolio moves (Thomas, 2013) creates growth, then profitability and henceforward cashflow to provide new endogenous investment resources.

In 1998, Siemens introduces value-based management as a top-down approach to corporate management. The first goal is to achieve EVA until 2001, in other words to obtain a return on capital employed that exceeds the weighted average cost of capital (Siemens, 2000). This goal will be maintained to date. Fit4More (Siemens, 2006) involves goals for all groups to grow with twice the rate of global domestic product growth and reach target margins. In 2007, Fit42010 includes goals to grow at twice the rate of the global domestic product and reach target margins, and new performance metrics such as return on capital employed between $14 \%$ and $16 \%$, and attain cash conversion rate of 1-growth rate (Siemens, 2007). In 2008, Fit42010 (Siemens, 2008) comprises performance metrics such as ROCE of $14-16 \%$, optimized capital structure, cash conversion rate of 1 - growth rate, twice global domestic product growth, best in class margin ranges, a reduction in selling, general and administrative expenses of $10 \%$. The same performance metrics are goals in 2009 (Siemens, 2009). In 2010, the Fit programs are replaced by Siemens One, which remains Siemens' strategy to date. With Siemens One, Siemens has established a financial target system that defines metrics for revenue growth, capital efficiency, profitability and the optimization of capital structure benchmarked against competitors (Siemens, 2010). In 2011, financial performance measures (Siemens, 2011) include revenue growth, capital efficiency and profitability - return on capital employed, return on equity, margins, capital structure, dividend policy. In 2012, financial performance measures include the same performance metrics (Siemens, 2012). In 2013, share buy-backs are added (Siemens, 2013). In 2014, performance metrics are extended to growth, capital efficiency, total cost productivity, capital structure, dividend pay-out ratio, profit margin ranges of businesses and are included in Vision 2020 (Siemens, 2014). In Vision 2020+ (Siemens, 2018), performance metrics remain growth, capital efficiency, capital structure, cash conversion rate, dividend pay-out ratio, profit margins of businesses.

Beginning with the Fit4More program since 2005, Siemens' strategic directions are called non-financial value drivers. In 1998, the top+ program comprises goals about portfolio measures and financial and capital measures (Siemens, 1998, 1999). In 2003, the Siemens Management System (Siemens, 2003, 2004) comprises three directions for years 2003-2004: innovation, customer focus and global competitiveness. Years 2005 - 2009, the Fit4More and Fit42010 programs embrace four pillars: 
performance and portfolio; operational excellence; people excellence; corporate responsibility (Siemens, 2005). The performance and portfolio pillar involve sales growth (twice the global domestic product) goals and margin goals (Siemens, 2005). The operational excellence pillar comprises the top+Siemens Management System with its sharp focus on innovation, customer focus and global competitiveness (Siemens, 2005). People excellence involves developing talent globally, strengthening leadership development, attaining high-performance culture and strengthening expert careers (Siemens, 2007). Corporate responsibility involves being best-in-class in corporate governance, business practices, sustainability and corporate citizenship (Siemens, 2005).

Since 2010, the directions in One Siemens are to focus on innovation driven growth markets, to get closer to customers and to use the power of Siemens (Siemens, 2010). The first in three major strategic directions, focusing on innovation driven markets now comprises Siemens' strengthening portfolio, being a pioneer in technology driven markets, providing a leading environmental portfolio. The second strategic direction in Siemens One is customer proximity, which bundles the measures previously called customer focus, global competitiveness, customer proximity. The third strategic area is using the power of Siemens and comprises empowering diverse and engaged people worldwide, standing for integrity, encouraging lifelong learning and development. The individual areas have been clearly measurable throughout time. Portfolio strategy (Siemens, 2010) is measured by portfolio focus on core businesses or growth; market leadership (number 1 or number 2 positions) of individual businesses; target margins for businesses compared to competitors. Environmental portfolio is measured by inherent sales (Siemens, 2010). Innovation is measured by research and development expenditure, by the number of patents (Siemens, 2003, 2004, 2010). Customer focus is measured mainly by the net promoter score, which measures customer loyalty for next businesses and the likelihood that customers would recommend Siemens to other customers (Siemens, 2007, 2010). Customer relationships also belong here and are deliberately called assets (Siemens, 2010). Global competitiveness involves targets for won orders, order backlog, placing division headquarters outside Germany. Since 1998, Siemens has reported new orders, which are the yearly sales for new business contracts. New orders and order backlog are goals for the distribution and customer relations organization for each Siemens business globally (Siemens, 2010). Order backlog represents the future revenues of the company resulting from already recognized new orders. Order backlog is calculated by adding the new orders of the current fiscal year to the balance of the order backlog from the prior fiscal year and subtracting the revenue recognized in the current fiscal year (Siemens, 2010). Order backlog is an indicator of future sales growth. Customer proximity is expressed as percentage of sales on emerging markets via business models like SMART, which involve placing all business there (Siemens, 2010). The next direction, using the power of Siemens comprises among others 
spending on employee education, employee empowerment or ownership corporate culture (Siemens, 2010).

As can be noted, these value drivers have been consistent in Siemens One and the previous strategies, Fit4More and Fit42010. These value drivers overlap with previous non-financial value drivers in the Fit4More and Fit42010 programs. In 2014, Siemens sets its strategy for the next years and perhaps decades (Siemens, 2014) and links it directly to value creation - for the short, medium and long term (Siemens, 2014) via focusing on business excellence short term; strengthen the core competencies in electrification, automation and digitalization midterm; scale up on the long term, that is intensify its efforts to seize further growth opportunities and tap new fields. In Vision 2020 from 2014 (Siemens, 2018), Siemens sets targets for improvement years 2014-2020 with respect to corporate governance (1 billion Euros cost reduction), strengthening portfolio (underperforming businesses fixed), execute financial target system (return on capital employed between $15 \%$ and $20 \%$; growth above most relevant competitors), expand global management (more than $30 \%$ of division and business unit management outside Germany), be a partner of choice for customers (the net promoter score up 20\%), be an employer of choice (Siemens engagement survey: employee engagement index, leadership and diversity index: $>75 \%$ ), strengthen ownership culture (increase number of employee shareholders by at least $50 \%$ ). These are the strategic priorities set in 2014 for 2020 and stated by Siemens achieved in 2018 (Siemens, 2018). Furthermore, Vision 2020+, Siemens sets new goals which comprise: growth in company value (increase in margin at industrial businesses by 2 points; Earnings per Share growth higher than revenue growth), sharpen business focus in electrification, automation and digitalization (accelerated comparable revenue growth plus 2 points compound annual growth rate), being a partner of choice for customers ( $20 \%$ improvement in customer satisfaction index), getting closer to markets (50\% of business headquarters outside Germany), live lean governance and driving continuous optimization (over 20\% efficiency improvement of support functions in scope), being an employer of choice (approval rating in employee surveys for specific topics, like diversity), ownership culture (approval rating in employee surveys for specific topics, like leadership). This list of value drivers is core, not exhaustive, as further value drivers have been communicated by Siemens but not on a steady basis.

Since 1999, Siemens has used an enterprise wide strategy, planning and budgeting process (Siemens, 1999). Within Siemens, businesses have profit and loss responsibility, and regional companies provide optimal support on a local basis (Siemens, 2007). At Siemens (Thomas, 2013), performance metrics align the strategy with the budget beginning with the market evaluation, continuing with strategy review, business target agreement and budget. 


\subsection{Competitor Benchmarking at Siemens}

Siemens benchmarks business units against the best in their industries (Siemens, 2000, 2001). Through systematic benchmarking, Siemens businesses measure themselves against the best in their industries and implement concrete measures to close any performance gaps (Siemens, 2000). With Fit4More, Siemens sets goals to all units to be as profitable as key competitors (Siemens, 2006). All Siemens groups are obligated to reach their target margins, short-term and long-term (Siemens, 2006). In 2007, as the Fit42010 program succeeds Fit4More, the margin targets Siemens groups receive as part of this program are benchmarked to reach competitors' levels, 14\%-16\% (Siemens, 2007). Competitor benchmarking is important enough to Siemens' strategy to be part of its summaries about past strategy: Siemens states that, by 2010, in terms of profitability, Siemens has caught up or overtaken competitors (Siemens, 2010). Year 2010 onwards, benchmarking continues to be pivotal in Siemens' strategy: with a financial target system and a goal of continuous improvement relative to the market and competitors, One Siemens is providing with the framework for success (Siemens, 2010). Within One Siemens, the explanation to Siemens' performance metrics directly linked to value is that Siemens aims to consistently outperform competitors and to set new standards for leadership in financial performance and operating strength (Siemens, 2010). The same is stated as the aim of One Siemens: to enhance the value of the company over the long term by continuously improving performance relative to the market and competitors (Siemens, 2010). In 2014, benchmarking performance to competitors remains key to Siemens' strategy (Siemens, 2014). In Siemens One, all performance metrics are benchmarked to competitors. In Vision 2020 (Siemens, 2018), Siemens' financial framework, ambitious financial goals are based on benchmarks.

\section{CONCLUSIONS}

Since 1998 going beyond 2025, value-based management has been the framework for Siemens' strategy. Throughout this while, Siemens' stated deliberate group strategies: top+ WIP, Siemens Management System, Operation 2003, Fit4More, Fit42010, Siemens One, Vision 2020, Vision 2020+ have been led by the overarching value creation goal. This means that Economic Value Added has been the leading company goal since 1998 beyond 2020. As Economic Value Added is one of the most important classic value-based management indicators, the Siemens case confirms classic value-based management is still valid in practice.

The Siemens case also shows a constant value driver tree used to appraise performance. Since 2005, Siemens' deliberate group strategies Fit4More, Fit42010, Siemens One, Vision 2020 and Vision 2020+ have been formulated as comprising goals expressed as performance metrics and value drivers as strategic directions that lead to the attainment of goals and are measured in these terms. Siemens' 
portfolio strategy has comprised targets about portfolio focus, leading market positions, business margins above targets, growth in electrification, automation and digitalization, environmental portfolio. Other value drivers have been innovation, with goals on research and development expenditure, number of patents; customer focus, with goals about the value of the net promoter score, customer relationships as assets; global competitiveness, with goals about won orders, orders back-log, percentage division heads outside Germany; customer proximity, with sales in emerging markets; Siemens employer of choice, measured in terms of approval rating, career programs, investment in education, investment in empowerment; ownership culture, with targets about number of employee shareholders, expenses for culture enhancing programs; functional efficiency, with targets for reduction in sales, general and administrative, reduction in support functions. These value drivers and the performance metrics that measure the success of these strategies have been constant at Siemens during 2005 -2025. The value drivers gauge in on Siemens' portfolio, business and functional strategies and the explanation for their persistence cannot span a book article. Value drivers are included in corporate culture, performance appraisals in what Siemens calls performance management. Deviations in value drivers from plan may be negative and thereby risks or positive and thereby opportunities. Further conceptual studies may be conducted about value drivers as the language of strategy and operations.

The research is limited by the complexity of the topic. The literature review may have become extensive and tackled managing for value, value creation, value destruction, value proposition, value delivery, value capture, value in the New Economy, value tools. The empirical evidence may have proceeded similarly and illustrate the details of value-based management at Siemens. However, such a research would have been considerably longer than this article, which is focused on the core of value-based management, both in theory and the practice of Siemens.

Value based management is a systems approach individualized by company. Whereas the theoretical guidelines do set a framework for managing for value, they agree value driver trees are unique to companies and industries. Classic studies on behalf of major consultants (Sten et al., 2003) point to the individualized nature of each value-based management case given by the value driver tree. Quantitative research, such as a study undertaken by Madden (2010) for 40 years on a significant sample of firms confirm value indicators such as adjusted discounted cash flow is still empirically valid. The Mc Kinsey studies state that whereas value indicators are the same, value driver trees tend to be unique. The goal of the "Valuation" book series 1994-2015 has been to find a general pattern for value driver trees on industry level or other activity type classification, where Mc Kinsey state this needs empirical evidence and further study. Value driver trees or performance indicators may measure business excellence and are the goals to be attained to reach it. The continuity of the Siemens value driver tree during 1998-2020 is remarkable, 
and further studies may find an explanation for this considering the changes in Siemens' business portfolio and organizational structure. Further studies may also highlight other issues related to value-based management at Siemens, such as corporate governance, employee performance appraisal and incentive systems, risk management.

\section{REFERENCES}

Armitage, H. M., \& Fog, V. (1996). Economic value creation: What every management accountant should know, CMA Magazine, October, Vol. 70, No. 8.

Arnold, G. (1998). Corporate Financial Management, Pitman Publishing, London.

Bannister, R. J., \& Jesuthasan, R. (1997). Is your company ready for value-based management?. Journal of Business Strategy, 18(2), 12-16.

Black, A., Wright, P, \& Bachman, J. (1998). In search of Shareholder Value. Managing the Drivers of Performance, Pitman Publishing, London.

Boston Consulting Group (2008). Value creators report. https://www.bcg.com/documents/file15314.pdf (accessed 04 2020).

Boulos, F., Haspeslagh, P, \& Noda, T. (2001). Getting the value out of value-based management, INSEAD survey.

CapGemeni (2016). The Digital Strategy Imperative: Steady Long-Term Vision, Nimble Execution, https://www.capgemini.com/consulting/wp-content/uploads/sites/30/2017/07/digital-transformation review-9.pdf (accessed 04 2020).

Chew, D. (1998). Discussing the Revolution in Corporate Finance, Wiley 1998

Christopher, M., \& Ryals, L. (1999). Supply chain strategy: its impact on shareholder value. The international journal of logistics management, 10(1), 1-10.

Condon, J., \& Golstein, J. (1998). Value based management-the only way to manage for value. Accountancy Ireland, 30, 10-12.

Copeland, T. E., Koller, T. M., \& Murrin, J. (1994). Valuation: Measuring and Managing the Value of Companies, John Wiley \& Sons

Copeland, T.E., Koller. T. M., \& Murrin, J. (2000). Valuation, Measuring and managing the value of companies, Third Edition, New York, John Wiley and Sons

Damodaran, A. (2007). Return on Capital (ROC), Return on Invested Capital (ROIC), and Return on Equity (ROE): Measurement and Implications, New York University Stern School of Business.

Damodaran, A. (2010). Applied Corporate Finance. Wiley.

Damodaran, A. (2011). Damodaran on Valuation: Security Analysis for Investment and Corporate Finance, Wiley.

Damodaran, A. (2012). Investment Valuation: Tools and Techniques for Determining the Value of Any Asset, Wiley.

Dominic, D., \& Favaro, K. (2006). Managing the right tension. Harvard Business Review, 84(12), 62-74.

Dominic, D., \& Favaro, K. (2007). The Three Tensions: Winning the Struggle to Perform without Compromise, Jossey-Bass.

Ehrbar, A. (1998). EVA - The Real Key to Creating Wealth, John Wiley and Sons, New York. 
Emerald (2020). Measuring Business Excellence. Retrieved on April 7th, 2020, from https://www.emeraldgrouppublishing.com/products/journals/journals.htm?id=mbe.

FCLTGlobal (2019a). Focusing Capital on Long Term. Retrieved April 5, 2020, from https://www.fcltglobal.org/.

FCLTGlobal (2019b). Focusing Capital on Long Term - members. Retrieved April 5, 2020, from https://www.fcltglobal.org/our-members/members.

Ittner, C. D., \& Larcker, D. F. (2001). Assessing empirical research in managerial accounting: a valuebased management perspective. Journal of accounting and economics, 32(1-3), 349-410.

Kaplan Financial Limited (2012a). Financial Management, BPP Learning Media.

Kaplan Financial Limited (2012b). Advanced Financial Management, BPP Learning Media.

Koller, T., Debbs, R., \& Huyett, B. (2010). The Four Cornerstones of Corporate Finance, John Wiley \& Sons.

Koller, T., Goedhart, M., \& Wessels, D. (2005). Valuation: Measuring and Managing the Value of Companies, John Wiley \& Sons.

Koller, T., Goedhart, M., \&; Wessels, D. (2010). Valuation: Measuring and Managing the Value of Companies, John Wiley \& Sons.

Koller, T., Goedhart, M., \& Wessels, D. (2015). Valuation: Measuring and Managing the Value of Companies, John Wiley \& Sons.

Kontes, P. (2010). The CEO, Strategy, and Shareholder Value, Wiley.

KPMG Consulting (1999). Value Based Management The growing importance of shareholder value in Europe.

Leahy, T. (2000). Making their Mark. Business of Finance, June, 1, 49.

Madden, B. J. (1999). CFROI Valuation (Cash Flow Return on Investment, A Total System Approach to Valuing the Firm), Great Britain, Butterworth-Heinemann Finance.

Madden, B. (2010). Wealth Creation: A Systems Mindset for Building and Investing in Business for the Long-Term, John Wiley and Sons.

Mankins, M. J., \& Steele, R. (2005). Turning great strategy into great performance. Harvard Business Review, July 2005, 2607.

Marsh, D. (1999). Making or Breaking Value. Management, 46(2), 58-59.

Martin, J. D., \& Petty, J. W. (2000). Value Based Management - The corporate response to the shareholder revolution, Harvard Business School Press.

McTaggart, J., Kontes, P. W., \& Makins, M. C. (1994). Value Imperative: Managing for Superior Shareholder Returns, The Free Press.

McTaggart, J., \& Gills S. (1998). Setting Targets to Maximize Shareholder Value, Strategy \& Leadership.

Nobel Prize Foundation (1997). Press release. Retrieved on April 20th, 2020, from https://www.nobelprize.org/prizes/economic-sciences/1997/press-release/.

Pitman, B. (2003). Leading for value. Harvard Business Review, 81(4), 41-41.

Rappaport, A. (1986). Creating Shareholder Value, The Free Press, New York.

Rappaport, A. (1992). CFOs and strategists: forging a common framework. Hanvard Business Review, 70(3), 84-91.

Rappaport, A. (1997). Creating Shareholder Value: a Guide for Managers and Investors, The Free Press.

Rappaport, A. (2006). Ten ways to create shareholder value. Harvard Business Review, 84(9), 66-77. 
Rappaport, A. (2009). CFOs and Strategists: Forging a Common Network. Harvard Business Review, March 2009.

Rappaport, A. (2011). Saving Back Capitalism from Short-Termism: How to Build Long-Term Value and Take Back Our Financial Future, Mc Graw Hill Professional.

Ronte, H. (1998). Value based management. Management accounting: Magazine for chartered management accountants, 76(1), 38-38.

Siemens (1998). Siemens annual report, https://www.siemens.com/investor/pool/en/investor_relations/downloadcenter/gb1998_d_1365091.pdf (accessed 2020).

Siemens (1999). Siemens annual report, https://www.siemens.com/investor/pool/en/investor_relations/downloadcenter/gb1999_d_1365092.pdf (accessed 2020).

Siemens (2000). Siemens annual report, https://www.siemens.com/investor/pool/en/investor_relations/downloadcenter/gb2000_d_1365093.pdf (accessed 2020).

Siemens (2001). Siemens annual report, https://web.lib.aalto.fi/fi/old/yrityspalvelin/pdf/2001/Esiemens.pdf (accessed 2020).

Siemens (2002). Siemens annual report, https://web.lib.aalto.fi/fi/old/yrityspalvelin/pdf/2002/Esiemens2002.pdf (accessed 2020).

Siemens (2003). Siemens annual report, https://www.siemens.com/investor/pool/en/investor_relations/downloadcenter/000_gb2003_e_1129103 .pdf (accessed 2020).

Siemens (2004). Siemens annual report, https://www.siemens.com/investor/pool/en/investor_relations/downloadcenter/e04_00_gb2004_1230305.p df (accessed 2020).

Siemens (2005). Siemens annual report, https://www.marketscreener.com/SIEMENS68827/pdf/.../Siemens_Annual-Report.pdf (accessed 2020).

Siemens (2006). Siemens annual report, https://web.lib.aalto.fi/fi/old/yrityspalvelin/pdf/2006/Esiemens2006.pdf (accessed 2020).

Siemens (2007). Siemens annual report, https://www.siemens.com/investor/pool/en/investor_relations/financial_publications/annual_reports/200 7/e07_00_gb2007.pdf (accessed 2020).

Siemens (2008). Siemens annual report, https://assets.new.siemens.com/siemens/assets/public.1490943496.339e69d3764fc430ecf507d9900c 57ce495d2846.sfm-annual-report-2008.pdf (accessed 2020).

Siemens (2009). Siemens annual report, https://www.siemens.com/investor/pool/en/investor_relations/e09_00_gb2009.pdf (accessed 2020).

Siemens (2010). Siemens annual report, https://www.siemens.com/investor/pool/en/investor_relations/siemens_ar_2010.pdf (accessed 2020).

Siemens (2011). Siemens annual report, https://www.siemens.com/investor/pool/en/investor_relations/siemens_ar_2011.pdf (accessed 2020).

Siemens (2012). Siemens annual report, https://www.siemens.com/investor/pool/en/investor_relations/siemens_ar_2012.pdf (accessed 2020). 
Siemens (2013). Siemens annual report,

https://www.siemens.com/annual/13/en/download/pdf/Siemens_AR2013.pdf (accessed 2020).

Siemens (2014). Siemens annual report, https://www.siemens.com/annual/14/en/download/pdf/Siemens_AR2014.pdf (accessed 2020).

Siemens (2018). Vision 2020+ Shaping the future Siemens, https://www.siemens.com/investor/pool/en/investor_relations/financial_publications/speeches_and_pre sentations/q32018/180802_Press_Analyst_Conference.pdf (accessed 2020).

Stewart, G. B. (1991). The Quest for Value. Harper Collins.

Stewart, G. B. (1994). EVA. Fact and Factory. Journal of Applied Corporate Finance, 7, 71-84.

Stewart, G. B. (2003). How to fix accounting-measure and report economic profit. Journal of Applied Corporate Finance, 15(3), 63-82.

Stewart, G. B. (2013). Best Practice EVA. Wiley.

Stern, E. (2011). The Value Mindset. Returning to the First Principles of Capitalist Enterprise. Wiley.

Stern, J. M., \& Chew, D. H. (2003). The Revolution in Corporate Finance. Wiley

Stern, J. M., Stewart III, G. B., \& Chew, D. H. (1995). The EVA® financial management system. Journal of applied corporate finance, 8(2), 32-46.

Stern, G. M., Shiely, J. S., \& Ross, J. (2003). The EVA Challenge. Implementing Value-Added in an Organization, Wiley.

Thomas, R. P. (2013). Performance Management FAU - Introduction RECON WS 2013/2014, Nuremberg, November 11, 2013.

Young, D. S., \& O'Byrne, S. F. (2000). EVA® and Value-Based Management A Practical Guide to Implementation, Mc Graw-Hill.

Zhao, F. (2004). Siemens' business excellence model and sustainable development. Measuring Business Excellence, Volume 8, Issue 2, 55-64. 